Open Access

\title{
Theory of open inclusive innovation for reciprocal, responsive and respectful outcomes: coping creatively with climatic and institutional risks
}

Anil K. Gupta*, Anamika R. Dey, Chintan Shinde, Hiranmay Mahanta, Chetan Patel, Ramesh Patel, Nirmal Sahay, Balram Sahu, P. Vivekanandan, Sundaram Verma, P. Ganesham, Vivek Kumar, Vipin Kumar, Mahesh Patel and Pooja Tole

\footnotetext{
* Correspondence: anilg@iima.ac.in Indian Institute of Management, Ahmedabad, India
}

\begin{abstract}
Given the economic squeeze world over, search for what we call frugal grassroots innovations in Honey Bee Network, has become even more urgent and relevant in the recent years. And, to shape this search, models and concepts like open innovation, reverse innovation (GE, Market-Relevant Design: Making ECGs Available Across India, 2009); (Govindarajan, Reverse Innovation: a Playbook, 2012); (Govindarajan and Ramamurti. Global Strategy Journal, 1: 191-205, 2011); (Govindarajan and Euchner, Res. Technol. Manage, 55: 13-17, 2012, Govindrajan and Trimble, 40(5), 5-11, 2012), embedded innovation (Simanis and Hart, Innovation from the Inside Out, MIT Sloan Management Review, 2009), extremely affordable, low-cost, frugal innovation (Honey Bee Network, 1989-2016, Gupta, 2000); (Gupta AK, How Local Knowledge can Boost Scientific Studies, 2007); (Gupta AK, Indian Hidden hotebd of invention, 2009a; Gupta AK, http://anilg.sristi.org/harnessing-stimulus-forpromoting-innovations-and-entrepreneurship/, 2009b) etc., have emerged over time. We wish to trace the evolution of the Open Innovation Theory (Urban and Von Hippel, Manag. Sci. 34(5), 569-582, 1988) in the context of the Honey Bee Network working on such ideas for over 26 years. The idea is to study the different strands of relationships between knowledge providers and seekers which make the system truly reciprocal, responsible and responsive. When systems become open, search cost for inclusive innovation will automatically come down and the knowledge system will also become more symmetrical and inclusive. Inclusive innovation for social development implies that new solutions should help in dealing with one or more of the five factors of exclusion: spatial, seasonal, sectoral, skill and social. These should also be accessible, affordable, available and adaptable to varying and differentiated user endowments and needs, besides being circular. One has to understand the interaction between natural, social, ethical and intellectual capital, situated in the institutional context of innovations: at, from, for and with grassroots level communities for defining inclusivity in the innovation ecosystem. A company or a community, when in need of an innovative solution to a local problem, may seek it from outside, develop it inside, or co-create/contract it out. The nature of reciprocity between knowledge and innovation exchange partners may (Continued on next page)
\end{abstract}


(Continued from previous page)

have different types of asymmetries (Bansemir and Neyer 2009). Different ethical principle enunciated in the Honey Bee Network may or may not be followed. The discourse on open innovation has been biased in the favour of corporates seeking ideas form outside rather than sharing their own innovation/knowledge as a public good or commons, or even at low cost with less-advantaged industry actors. In this paper, we reflect on such biases that companies and scholars have developed and propose a framework to temper it. The need for such a correction becomes even more important when various kind of climatic, institutional and market risks are making socio-economic systems more fragile and vulnerable to various uncertainties and fluctuations.

Coping with risks is significantly related to malleability of innovations. The process of evolving and nurturing innovations may have a bearing on their eventual adaptability to user. We argue that when both technology platform and application domains are known well, the incubation model works. Generally, through this process, incremental innovation grows better. But, when both are unknown or are ambiguous, sanctuary model works better. In incubators, the chaos is outside and the order is inside. In sanctuary, it is the opposite. It is not very surprising that sanctuary nurtures innovation which is more suited to fluctuating climate and market-uncertain environments.

Innovations don't have relevance only at artefactual level. One can learn at metaphorical, heuristic and gestalt levels too. Building bridges between formal and informal knowledge systems poses a unique challenge in designing reciprocal and responsible open innovation platforms? This paper pleads for more reciprocal, respectful and responsible exchanges of knowledge between formal and informal sector adding value to the contributions of grassroots green innovators.

\section{Introduction}

The frugality (or low-cost, affordable nature of innovations) emerged as an inalienable feature of grassroots innovations 26 years ago while setting up the Honey Bee Network. The Network recognised that materially-constrained people had no choice but to intensify the knowledge input and economise the material costs. It has taken the world a long time to recognise the merit of frugal innovations, partly triggered by the global economic squeeze and partly, by the consumer preference in emerging economies where growth potential is evident. The frugality is not a transient concept: When under pressure, be frugal, else, be wasteful or indifferent to the concept of extreme affordability! It is important to stress that frugality is not just about the affordability. A five-cent sachet of detergent soap or a mouth freshener may be extremely affordable. It may appear to be frugal too. But, when one calculates the cost of collecting the plastic packaging material from thousands of rural and urban locations, this may turn out to be an extremely costly innovation for the environment. Therefore, frugality must blend affordability with circularity (the ability of waste being repurposed, recycled or incorporated in different value chains without affecting the environment adversely). The openness of knowledge system at community level facilitates emergence of open and reciprocal innovations for dealing with climatic, institutional and market risks.

In this paper, we provide a grassroots perspective to the open, reciprocal, responsive and respectful innovations, which are often very frugal. However, we must clarify at the outset that not all grassroots innovations are frugal or even sustainable; though, most 
are. The institutional platforms created by the Honey Bee Network will be explained so that other countries and communities can build upon this experience and develop their own endogenous models.

\section{Part I}

Theory of open, reciprocal, responsive and respectful innovations

When the Honey Bee Network volunteers started looking for odd balls, the creative people who had solved a local problem through their own efforts, the openness of the communities and innovative individuals to share their ideas with us manifested clearly (Gupta 1988; Gupta 1995a; Gupta 2000; Gupta 2011; Gupta 2006; Gupta and Mashelkar 2005). Why should somebody share one's ideas with others, with no expectation of returns to begin with? It is not entirely an altruistic behaviour. Sharing generates potential for feedback and thus improves the knowledge base. People share when they trust. The trust emerges when people seeking knowledge are genuine learners, and iterative exchanges and creation of interdependence generate confidence (Mayer et al. 1995). Without sharing the prior knowledge and ideas, search for new ideas often does not yield results. Sharing, therefore, may precede seeking. Openness becomes reciprocal when both sides are willing to share with each other. The responsibility comes when the knowledge shared is used by both the parties - the provider and the user - with responsibility towards the community, nature and also, for the future generation. Not everybody may discharge one's responsibility towards each stakeholder equally well. When the seeker and the provider of the knowledge and the innovations develop mutual trust and responsibility, they also become respectful towards each other's cultural and moral sensibilities and constraints. However, in practice, such mutuality is rarely obtained.

Keeping aside the open, reciprocal and responsible open innovation experience of more than 26 years of Honey Bee Network experience, a brief look at the recent the recent writings shows a bit narrower definition of the subject. Authors have treated openness as willingness to use knowledge/ideas from customers, orther organizations, $\mathrm{R}$ and D institutions, suppliers/vendors etc., outside the firm (West, Salterb, Vanhaverbekec, and Chesbrough 2014; Chesbrough 2003, 2006, 2011; Urban and von Hippel 1988; von Hippel 2002, 2005; Von Hippel et al. 2011; Dahlander and Gann 2010; Baldwin and von Hippel 2011; De jong et al. 2008; De Wit et al. 2007; Hyo et al. 2016). Yun et al. (2010), and Yun and Avvari 2012; Bughin, Chui and Johnson, 2008; Gassman and Enkel, 2004; Immelt, Govindrajan and Trimble, 2009; Govindrajan and Trimble, 2012; West and Bogers, 2014; Pansera, 2013; Di Minin, Frattini, and Piccaluga 2010. In an interesting contribution traced the experience of open innovation system in small and medium industry, a rather neglected sector in literature on the subject in Korea, particularly during their transition to high tech domains. Laursen and Salter (2006) found a crivilinearnar experience in performance among firms searching innovations from outside. In a more recent study, Laursen and Salter 2014, find those firms which are able to protect their own intellectual property (that they don't let their knowledge be leaked to outsiders) are able to get into more viable collaborations for seeking knowledge and ideas from outside. This apparent paradox of open innovation is conceptualised as high outside-in but low or no inside-out in the theoretical framework presented here. 
Let us look at binding constraints at different levels and varying degree of openness in sharing one's knowledge and innovative solutions. We discuss four key conceptual schemes in this regard: (a) Innovation playground: Inside out vs. outside in (Gupta 2013; Gupta 2015a, b; Gupta 2014b; Gupta 2016); (b) Reciprocity vs. responsibility (Gupta 2003; Gupta 2014a; Owen et al. 2013; Esders 2013); (c) Knowledge interface across community, public and individual domains (Gupta and Sinha 2002; and (d) Communication and power one way, two way and no way communication, with one way, two way and no way power, Gupta 1980).

\section{(a) Innovation playground: Inside out vs. outside in}

Innovation exchange between corporations and communities can be guided by various ethical and efficiency considerations. In the available literature, openness of corporations to seek ideas from outside on various terms is considered a kind of open innovation policy. Even if corporations do not share what they did with that knowledge, it is still considered open. On the other hand, von Hippel and others have considered willingness of users to share their derivative innovations with the corporations manufacturing those products without any reciprocity as a sign of openness in innovation (Bogers and Bastian, 2010; von Hippel, 2005). We deal with four strands of exchanges: (i) Low inside out - low outside in; (ii) Low inside out - high outside in; (iii) High inside out - low outside in; and (iv) High inside out - high outside in.

(i) Low inside out - low outside in In this case, the corporations are behaving like an ostrich, unwilling to share and equally unwilling to learn from outside. Such organisations are not very resilient and are often found vulnerable to various climatic, institutional and market risks. In the absence of a large repertoire of coping strategies within organisations, they buckle in. It is not before too long that such organisations disappear. The communities which exhibit similar behaviour go through 'involution' instead of 'evolution' and may either disintegrate or get incorporated under some other dominant identities.

(ii) Low inside out - high outside in

The sponge like behaviour is shown by the organisations in such an exchange relying on crowdsourcing (How 2006; Poetz and Schreier 2012). The corporations are willing to learn from outside at different terms, including one-time or milestone-based payment, just a thank you note, non-monetary recognition, etc. Many large corporations use this kind of crowdsourcing strategies. They claim to follow open innovation but do not share much of their own knowledge with the outsiders or the providers of even knowledge, idea and innovations. They seldom let the external idea or innovation provider know as to what they did with the idea, how much wealth did it generate, if at all, and how many other derivative innovations were triggered by that innovation. If they shared all this, the selfrespect of the knowledge/innovation provider will go up and may be, she would value her own ideas more than before. Since a large number of us are worst enemies of our own ideas, in the absence of such feedback, we do not know the cost of ignoring such ideas. Despite being a dominant paradigm, one cannot expect 
such an institutional arrangement to last very long. Eventually, some of the promising idea providers might allocate their energies elsewhere.

(iii) High inside out - low outside in

The pollinator kind of behaviour, evident in this case, is one of the very benign models of open innovation. The companies like Tesla (Quinn and Brachmann 2014; Moritz et al. 2015) shared their patents in open to encourage competition and expand infrastructure (of charging stations for electrical car) and generate new knowledge about how others use the knowledge produced by the pollinator. They create knowledge public goods, without generally any expectation of reciprocity. There is no corporation or other formal research and development R\&D institution which cannot share some of its knowledge with outsiders, or create knowledge public goods. Being the industry leader, lesser willingness to learn from outside may prove to be a costly error in the long term.

(iv) High inside out - high outside in.

This is the most mutually-empowering model of innovation policy in which one is willing to learn a lot from outside and one is equally willing to share a lot. This requires a big heart and a big mind (dil bada, dimag bada). Such organisations are likely to be more sustainable in the long run. Their growth and development is contingent on a constant iterative cycle of learning and sharing. The Honey Bee Network signified this approach of open innovation relentlessly for the past 26 years. Even when National Innovation Foundation (NIF) facilitated the filing of patents using the concept of 'technology commons' (Sinha 2008; Gupta 2007), it ensured that people-to-people copying was not only allowed but also encouraged. People-to-firm exchange of knowledge and ideas was to take place through licensing. It hybridises the open-source model with stratified IP-based closed model.

It is important for the corporate leaders to recognise the value of ideas from outside, including from the grassroots level. But, without mutual respect and responsibility, a reciprocity may not be symmetrical. It is to overcome the inherent institutional asymmetries that one may need benevolent brokers/intermediaries (like SRISTI, GIAN, NIF, SEVA, Palle Srujuna etc., members of Honey Bee Network) to mediate, moderate and monitor the exchange of ideas between the formal and informal sectors.

(b)Reciprocity vs. responsibility

The reciprocity can be generalised or specific. Many studies have looked at reciprocity among team members within firm but not among firm and outsiders, particularly in the informal sector (West and Bogers 2014, except Schaarschmidt 2012, who looks at reciprocal exchange in open software community, a subject well researched). Neglect of reciprocity between formal sector (firm) and the informal sector (grassroots idea/knowledge or innovation providers) in the recent reviews makes this case of genuine reciprocal and responsible innovation even more worthy of urgent attention (Gupta 1998; Gupta 2003; Gupta 2006; Gupta 2009a; Gupta 2012). A community may provide a herbal 
innovative drug for treating a disease. The corporation may provide its own solutions for the same disease to the community. This is a specific exchange. Alternatively, the corporation may build a school, organise a plant identification campaign or workshop in lieu of the community providing a herbal lead. In some cases, the rights of individuals may be intertwined with the rights of the communities, particularly among indigenous/ local people. In such cases, the ability of a corporation to deal with risk and uncertainty can be augmented if it accesses such knowledge from the community elders. It may not necessarily provide modern weather station data or some such knowledge, which communities may or may not value. It may build either infrastructure, or create knowledge/innovation databases in local languages in lieu of specific technological leads. Such generalised reciprocities tend to strengthen the individual and community capabilities beyond the specific technological domain. In some cases, this may embolden the community to negotiate the favourable terms of innovation exchange with formal sector. There are four situations where reciprocity may be significantly high or marginal in nature vis a vis degree of varying responsibility likewise such as (i) High reciprocity and low responsibility; (ii) High reciprocity and high responsibility; (iii) Low reciprocity and high responsibility, and (iv) Low reciprocity and low responsibility.

(i) High reciprocity and low responsibility

There are many public organisations, open-source databases and other such platforms which share information and also receive it without any restriction. But, when it comes to responsibility for consequences, these generally use the disclaimer about their limited ability to take responsibility for consequences. This problem becomes complex when people using this innovation or knowledge database do not have adequate ability to interpret the claimed validity by formal sector or take the risks involved. However, on the balance, such a model of open innovation does promote societal learning a great deal and the benefits far outweigh the costs. The transaction costs of both provider and receiver of knowledge are also low in this model. The problem is that there are not too many such open databases of innovations yet. The database on common property institutions innovation (sristi.org/cpri) is one such database. It is a collection of indigenous, common property institution case studies from around the world, mobilised mainly from secondary but, some from primary sources too. The responsibility for accuracy rests with the author. The reciprocity is high because nobody has objected to the inclusion of their work with full credit in this database. It helps researchers and community-based organisations that are looking for new heuristics for collective management of natural resources at local level. Such open-innovation platforms do fertilise the ground for imagination and help in cross-pollination of ideas.

(ii) High reciprocity and high responsibility

This is a case where provider and user of knowledge are equally responsible and reciprocal. If a user of a product made by a company innovates to add some new feature, new function, modify the form to fit new niches, overcomes some of the deficiencies or finds some new applications and shares these with the manufacture, he 
has performed a highly responsible act. If the manufacturer evaluates it, shares the feedback and in some cases, agrees to co-create the solution with benefit-sharing, then it will be a case of high reciprocity and high responsibility (Gupta 2000, 2012). It is a different matter that in the literature on open innovation, such cases are few. The Honey Bee Network is an exception. A large number of ideas contributed by children and many grassroots innovators have been valorised by the team of professionals in NIF, Society for Research and Initiatives for Sustainable Technologies and Institutions (SRISTI) and Gujarat Grassroots Innovation Augmentation Network (GIAN) with full credit and benefits to the idea providers. Openness on both the sides has led to mutual trust and responsibility. More than 800 patents and other forms of protection (e.g. Plant variety protection for crop varieties developed by the farmer breeders) have been extended to children and grassroots innovators through pro bono help of the patent attorneys, using public funds by NIF in the name of the innovators. Entire license fee of about $10 \%$ of these innovations, so far commercialised, has also been shared with the innovators completely. ${ }^{1}$

The techpedia.sristi.org has information about 190,000 engineering projects, pursued by 550,000 students from over 600 institutions in India. This is one of the largest open-innovation platforms which has authentic information sourced from various academic institutions. Similarly, the Gandhian Young Technological Innovation Awards are listed at gyti.techpedia.in with mutual responsibility and reciprocity, among the students, their guides and SRISTI.

(iii) Low reciprocity and high responsibility

This is a case where a teacher or a formal sector technologist shares all that he knows and the student or community member asks about all that he does not know. Both sides perform their roles in knowledge economy and share ideas to reinforce shared learning systems. But, there is not much that they are obliged to reciprocate to. There is an exchange of ideas but with little, if any, specific or generalised reciprocity. Online learning platforms for start-ups and innovators can be very useful for the open innovation systems. However, there are not too many examples where start-ups have shared their problems and the innovative ways in which they solve them as an open-source learning material for the other budding innovation-based start-ups.

(iv) Low reciprocity and low responsibility

This category signifies a case where many corporate actors may benefit from the user-driven innovations (often without any acknowledgement, credit or benefit/ knowledge sharing). The users also may not go out of their way to share. Many roadside mechanics routinely modify the features of various automobiles or gadgets which the manufacturer may not have taken note of. For instance, the cycle manufacturers have generally ignored a feature of footrest for children sitting on the horizontal bar. Their legs do not reach the mudguard or the triangular rod. Mechanics add a simple strip which can be horizontal to the triangular bar and, when turned at $90^{\circ}$, becomes a footrest. The design of the cycle has not changed nor the users have pursued with the manufacturers to bring about this and other features. So much of design inertia can be explained by mutual apathy. 
The theory of open innovation has more or less ignored the relative contribution of reciprocity and responsibility so far. By bringing this dimension, the ecosystem for open innovation becomes more empathetic and empowering for all the actors (Macnaghten et al, 2014). The result is that learning quotient goes up significantly. The meaning of a responsible act may not always be shared among all actors in the same way. The corporations used to dealing with outsiders in a contractual language may perhaps restrict their responsibility to the clauses of a knowledgeexchange agreement. Some of them may not even recognise the need for building capacity of knowledge provider, particularly in informal sector, before agreeing to enter into an exchange of knowledge with them (Gupta, 2007). The concept of prior-informed consent (PIC) may be interpreted too narrowly in several cases. At the same time, there are organised sector members who may understand and appreciate the need for going beyond the strict call of the duty and thus behave in a more responsible manner than may be the trend in the industry. The communities can also stint in disclosing their full knowledge if the trust is lacking and thus affect its scientific and technological development. The act of not just sharing knowledge but extracting natural resources within sustainable limits may or may not be recognised as a part of community responsibility. Thus, both sides have to match reciprocity and responsibility; those who have more power have a greater responsibility in any case for ensuring the fairness of exchange in an open-innovation system.

(c) Knowledge interface across community, public and individual domains

The three domains of knowledge system are contested as shown in the Table 1 (Gupta and Sinha 2002). The knowledge may be restricted to one or a few individuals or a whole community or may be in public domain. The outsiders such as academics or industry representatives may seek the traditional knowledge or contemporary innovations from local communities with or without the consent of community elders. They may then publish a paper disclosing the innovation and thus prevent the community from having any opportunity to protect their knowledge rights or negotiate knowledge transfer at mutually-agreed terms. This kind of asymmetrical knowledge exchange has been going on for centuries and is still in vogue. The openness of an innovation system in this case does not favour knowledge provider as much as knowledge seeker. The situation becomes more complicated when we take the interrelationship of different property rights in knowledge as well as resources (See Table 1).

The open-innovation framework has not grappled with the complexity of knowledge and innovation exchange when knowledge and resource rights are not co-terminus. As

Table 1

\begin{tabular}{|c|c|c|c|c|}
\hline & & \multicolumn{3}{|c|}{ Knowledge rights/domains } \\
\hline & & Private & Common & Public \\
\hline Resource & Private & & & \\
\hline \multirow[t]{2}{*}{ Rights/domains } & Common & & & \\
\hline & Public & & & \\
\hline
\end{tabular}


a herbal healer, I may have knowledge about therapeutic uses of plants growing in my own garden, my village and on public lands such as roadside or public forest. In different cases, my ability to use knowledge and improving it depends upon my ease of access to the resource. In the absence of flexible access to resources, I may not be able to use the knowledge even if I have it. When I exchange my knowledge with a company, they may like to test and validate it before reciprocating in material/non-material forms with individuals or communities. My ability to share knowledge may also be constrained by community norms and sanctions. It is desirable to take into account the complexity of knowledge and resource-right regimes/domains so that reciprocity and responsibility of various partners can be assigned and apprised in a fair and just manner. This is an evolving field where ethical norms will play as much, if not more, role as institutional and professional norms.

(d) Communication and power one way, two way and no way communication, with one way, two way and no way power (See Table 2, own compilation, adapted from Gupta 1980).

This framework was developed way back in 1980 while dealing with the interplay between communication and power among the actors in formal and informal sectors. ${ }^{2}$ The ideal case is when both sides have equal power (two-way power) and both sides have the freedom or agency and ability to communicate (two-way communication). Under such conditions, mutual control, accountability and responsibility are fixed so that no one side dominates the discourse.

One-way communication - One-way power is a highly authoritarian model in which those who rule or have authority and power decide what is communicated to others. The recipient has to receive said communication passively. Two-way communication and one-way power could be a situation wherein a scientist or corporate manager may listen to the feedback of the farmers/users but, ultimately exercises his/her authority to decide which feedback to act upon and which to ignore. The possibility of someone having power and not asserting or communicating it is almost zero. If one has power then it will flow through communication mode and meaning. On the other hand, oneway communication with two-way power is possible situation in a democratic election in which the leaders may convey their agenda and the voters may show their power through voting rather than verbally communicating it. Next, one-way communication with no power flow either way represents a tom-tom beater (an announcer on a railway station or any public place) who announces messages to people in a locality, without any power to influence the actual content or its interpretation. Another example of this dynamics is the people who manage propaganda or dissemination, without having the power to influence the content. Two-way communication with two-way power is

Table 2 Communication and power

\begin{tabular}{lllll}
\hline \multirow{2}{*}{ Communication } & & \multicolumn{2}{c}{ Power } \\
\cline { 3 - 5 } & One-Way & Two-Way & No-Way \\
\hline & Two-Way & Authorization & Fearful Dictator & Street singer or Tom Tom beater \\
& No-Way & Power of silence & Impossible & Indifference \\
\hline
\end{tabular}


perhaps the most sustainable and democratic arrangement. Mao Tse-tung called this the mass-line concept. The brigade was accountable to commune and vice versa. The two-way power makes it democratic and two-way communication makes it humanitarian. The Honey Bee Network has tried to evolve into a social movement, with such norms of horizontal and vertical accountability Gupta 2002, 2007. Gandhi $j i$ called a similar approach the gram swaraj in which the village community was expected to resolve a lot of common issues through collective will and mutual respect, without direction or interference from higher levels of authority. Both the state and the local bodies maintain their respective domain of power and communicate with each other through mutual responsibility and accountability.

In our context, two-way communication - two-way power will mean that farmers or industrial innovators at the grassroots level will have the power to comment upon and correct, if need be, the action-research agenda designed by scientists, technologists and firms, and vice versa. The scientists and technologists will also have the power to shape the agenda of farmer experimenters and innovators. The open innovation platforms have seldom looked at power asymmetries while evaluating the reciprocity and responsibility in knowledge exchange.

\section{Part II}

\section{Coping with risks through open innovation}

The climate change risks affect institutional and community choices in different sectors over space and time in less predictable manner than before. The coping strategies described elsewhere (Dey and Gupta 2016; Dey et al. 2015b and 2015c; Dey et al. 2015d, e, Gupta 1984, Gupta 1985, Gupta 1988; Gupta 1990) include intra household, interhousehold, community and public-level adjustment strategies. The companies and other formal institutions also hedge their risks through various market and non-market instruments. The global concern for frugal innovations shows that long-term, risky $R \& D$ projects are favoured less now. To reduce the cost of generating innovative solutions emerging in the market place, many firms are trying to use open-innovation platforms for sourcing ideas from outside. Some of them are also trying to learn from grassroots innovators. However, for the reason mentioned earlier, the norms of knowledge exchange because of the power asymmetries are not able to diffuse the risks of informal sector vis-à-vis the formal sector. The Honey Bee Network model provides several strategies for coping with risks, particularly in agriculture sector by using reciprocal, responsible and respectful norms of knowledge exchange. Various innovations at grassroots level provide extremely-affordable solutions for generating biomass energy, processing food, using various biomaterials for industrial and consumer applications, besides developing solutions for farm operations. Since majority of the grassroot innovators are materially constrained, they tend to leverage the open knowledge more than the material resources. The coping strategies in the wake of climate change require a portfolio of choices which can be shuffled with minimum transaction costs, in a much more flexible manner. This requires very agile institutional response, possible only when mutual trust between the formal and informal sectors is maintained at a very high level.

Failure of crops, unexpected mortality of animals and other kinds of losses during extreme whether conditions can put people under significant loss and debts. Once the market rating of community members goes down, the institutional response may 
become sluggish. It has been argued earlier that risk averse institutions can never help risk averse individuals or groups (Gupta 1988). The challenge for open innovation theory is to find ways in which short term vulnerability of poor people in informal sector does not disenfranchise them from various entitlements and opportunities, both in the short and long terms (Dey and Gupta 2015; Dey et al. 2015a; Gupta 2014c). Different kinds of risk funds can help unleash the entrepreneurial ability of knowledge-rich, economically poor people. Micro Venture Innovation Fund (MVIF), set up by NIF in 2003 with the help of SIDBI, provides risk capital to grassroots innovators under single signature and without any collateral security. Such models for both monetary and nonmonetary help for empowering innovators are urgently needed in various parts of the world. Community workshops, Fab Labs, wet labs, etc., are needed to add value to local knowledge so that partnership with formal sector may become much more viable than in the case when knowledge or ideas are in the raw form. There is a need for intermediary organisations such as NIF, GIAN or SRISTI to reduce the transaction costs of communities and corporations.

Earlier studies by Gupta (1981, 1990, 1995b), Gupta and Mathur 1984, Dey (2015), and Dey and Gupta (2016) have shown that community-coping strategies in drought or flood-affected climate risk regions include a portfolio of material and non-material opportunities which are aimed at individual and groups at different stages of production cycle. But, effectiveness of portfolio diversification is closely contingent on openness of knowledge exchange among different community members as well as external individual and institutional actors. The resilience of the community members to assimilate the consequences of climatic risks and not only cope with them but also transcend them depends upon the flexibility and agility of the support system whether in public or private sector. If the formal sector is not open enough, much less being reciprocal and responsible, then the ability of community to make concurrent changes, whether for salvaging the affected crops or ensuring better returns from future options, is severely constrained. The investment required for generating location-specific contingent options is often missing in the market place. Given the long tail of innovation, the return to the niche-specific innovations is low (Fleming, 2007). Therefore, unless organisations have a much diversified portfolio coupled with public incentives, we may not be able to augment the resilience at community level. In the longer term, this will constrain the market size and adversely affect the growth. One can hypothesise that open innovation may flourish more when the timeframe is long.

When the resources are mobile or fugitive e.g. in fisheries or livestock sector, the coping strategies have to be even more robust and institutional in nature. The models of open innovation in such cases will have to be premised on knowledge networks and inter-organisational networks. In a network economy, depending upon how widely and easily information across different nodes is exchanged, the quick turnaround of ideas and their applications in risky situations can take place through iterative and interactive knowledge system. Greater the mobility and fugitiveness of the resources, greater is the need for network efficiency. Without sufficient trust as mentioned earlier, neither responsibility nor reciprocity will follow to achieve such a kind of network efficiency. Assuming that formal and informal sectors have arrived at a reasonable faith in each other's capabilities and commitment, the prospect of adding value to emerging innovations can be studied through the interface between technological domain and available 
technological platform. There are four possible situations in this regard: (1) Domain is known and technological platform is also known; (2) Domain is unknown but platform is known; (3) Domain is known and platform is unknown; and (4) Neither domain nor platform is known.

In the first case of known domain and known technological platform, incubator models of value addition may work. When domain is not known and platform is known, the augmented R\&D outsourcing and consortium-based innovation development can take place. When domain is known and the platform is not known, internal $R \& D$ in a competitive mode may help. When both are unknown, the sanctuary model is likely to work better. In the incubation model, the chaos is outside and the order is inside. For incremental changes, such models can work. In the sanctuary model, chaos is inside and the order is outside. In such a framework, a lot of randomness is leveraged to generate new configuration of knowledge and institutional network to find solutions. It requires a very high degree of trust and willingness to share one's ignorance. Since domain knowledge is of less consequence, the participation of large number of actors in the innovation system is possible.

When we compare the institutional condition under high risk and institutional context of sanctuary model, we can surmise that the institutional and technological innovations may require the freedom of sanctuary model.

\section{Conclusion}

In this paper, we have argued that the conventional understanding of open innovation theory is highly inadequate for dealing with emerging challenges in leveraging contingent conditions of climate risks, asymmetry of knowledge and power and lack of reciprocity and responsibility among the formal and informal actors. To deal with the greater complexity and need for higher frugality and circularity (McDonough and Braungart 2009), the open innovation theory will need substantial evolution in the direction indicated in the paper. The degree of openness among different actors in different domains and at different levels in the society may influence the strategies for harnessing the power of co-creation and network management for distributed knowledge system. The innovation clubs of youth to search, spread, celebrate innovations and sensing the unmet social needs will provide the context in which open innovation system will flourish. One cannot learn just at artefactual level from an innovation but also learn at analogic or metaphorical, heuristic or gestalt level. That is why larger corporations have been trying to learn from the Honey Bee Network lately.

In the coming decade, those companies and communities which are able to balance the need for reciprocity and responsibility, and respect each other will eventually succeed in creating robust, resilient and agile shared economy.

\section{Endnotes}

${ }^{1}$ The patents are not used to stifle people-to-people learning. In fact, self-employed people are not only allowed but also encouraged to copy each other's ideas. Only the tech transfer to firms or organised sector are through licensing.

${ }^{2}$ Gupta 1980; Gupta 2016, Grassroots innovations: Minds on the margin are not marginal minds, New Delhi: Penguin Random house, 


\section{Acknowledgement}

The publishing fee of this paper was supported by the DGIST R\&D Program of the Ministry of Science, ICT and Future Planning(16-IT). Authors are grateful to umpteen grassroots innovators, staff of SRISTI, GIAN and NIF for contributing to the valuable insights shared in this paper. The responsibility for any inadequacy and limitations rest with the senior authors Anil Gupta and Anamika R Dey. This work draws upon doctoral thesis research being pursued by Anamika R Dey

Received: 30 May 2016 Accepted: 24 June 2016

Published online: 26 August 2016

\section{References}

Baldwin, C., \& von Hippel, E. (2011). Modeling a paradigm shift: From producer innovation to user and open collaborative innovation. Organization Science, 22(6), 1399-1417.

Bansemir, B, \& Neyer, AK. (2009). From idea management systems to interactive innovation management systems: Designing for interaction and knowledge exchange. IDEA, 1, 1-2009.

Bogers, M, Afuah, A, \& Bastian, B (2010). Users as innovators: a review, critique, and future research directions. Journal of Management. doi:10.1177/0149206309353944

Bughin, J, Chui, M, \& Johnson, B. (2008). The next step in open innovation. McKinsey Quarterly, 4, 112-122.

Chesbrough, HW. (2003). Open Innovation: The New Imperative for Creating and Profiting from Technology. Boston: Harvard Business School Press.

Chesbrough, HW. (2006). The era of open innovation. Managing innovation and change, 127(3), 34-41.

Chesbrough, HW. (2011). Bringing open innovation to services. MIT Sloan Management Review, 52(2), 85

Dahlander, L, \& Gann, DM. (2010). How open is innovation? Research Policy, 39(6), 699-709.

De Jong, JP, Vanhaverbeke, W, Kalvet, T, \& Chesbrough, H. (2008). Policies for open innovation: Theory, framework and cases. Tarmo Kalvet.

De Wit, J, Dankbaar, B, \& Vissers, G. (2007). Open innovation: the new way of knowledge transfer? Journal of Business Chemistry, 4(1), 11-19.

Dey, AR. (2015). Coping creatively with Climate Risks: Farmers' adjustment with floods in eastern India, paper presented at the third ICCIG, 2015, IIM Ahmedabad, accepted for inclusion in the proceedings.

Dey, A, \& Gupta, AK. (2015). Empathetic innovations for sustainable communities: Heuristics for extremely affordable innovations. In P. Stebbing \& U. Tischner (Eds.), Changing Paradigms: Designing for a Sustainable Future. Cumulus: Helsinki.

Dey, A, \& Gupta, A. (2016). Open Innovation at different levels for Higher Climate Risk Resilience (STS special issue (SSCI) of SOltmC and CSCOM 2016). forthcoming.

Dey, A, Singh, G, \& Gupta, AK. (2015a). Coping creatively with Climate Risks: Farmers' adjustment with floods in eastern India, paper presented At the third ICCIG. Ahmedabad: IIM.

Dey, A, Singh, G, \& Gupta, AK. (2015b). Innovative incentives for in-situ conservation of agro-biodiversity for strengthening community adaptation with climate change. Ahmedabad: IIMA, Mimeo.

Dey, A, Singh, G, \& Gupta, AK. (2015c). Role of Intermediaries in bridging and blending formal and informal sectors for an Inclusive Innovation system presented at Third ICCIG with Dharambir Kambhoj. Ahmedabad: IIM, mimeo.

Dey, A, Singh, G, \& Gupta, A. (2015d). Women in climate change adaptation: role reversal from beneficiaries to advisors. Ahmedabad: IIM, Mimeo.

Di Minin, A, Frattini, F, \& Piccaluga, A. (2010). Fiat: open innovation in a downturn (1993-2003). California Management Review, 52(3), 132-159.

Esders, M. (2013). Reciprocal and Responsible Innovation for Sustainable and Inclusive Development. Vikalpa, 38(3), 120-122.

Fleming, L. (2007). Breakthroughs and the" long tail" of innovation. MIT Sloan Management Review, 49(1), 69.

Gassmann, O, \& Enkel, E. (2004). Towards a theory of open innovation: three core process archetypes. R\&D management conference, $6(0), 1-18$

Govindarajan, V, \& Trimble, C. (2012). Reverse innovation: a global growth strategy that could pre-empt disruption at home. Strategy \& Leadership, 40(5), 5-11.

Gupta, AK. (1980). Communicating with farmers-Cases in agricultural communication and institutional support measures. New Delhi: IIPA.

Gupta, AK. (1981). Social Effects of Rural Projects Monitoring Through People's Participation. In International Review of Administrative Sciences, No.3 (Vol. XLVII, pp. 241-251).

Gupta, AK. (1984). Socio-Ecological Paradigm for Analyzing Problems of Poor in Dry Regions, Ecodevelopment News, (Paris) 32-33, March 1985 (pp. 68-74).

Gupta, AK. (1985). Socio-Ecological Paradigm for Analyzing Problems of Poor in Dry Regions, Ecodevelopment News, (Paris) No.32-33,pp 68-74.

Gupta, AK. (1988). Survival Under Stress: Socio Ecological Perspective on Farmers' Innovation and Risk Adjustments, W.P. No. 738 (International Congress on Plant Physiology, New Delhi,1988., revised version published in Capitalism, Nature and Socialism,5. 1990, pp. 79-96).

Gupta, AK. (1990). The Right To Resource: Peasant Knowledge, Protocol of Its 'Extraction' and Ethics of Collaboration In Extractions. W.P.No.851, January 1990, p12. Also published in brief as Peasant Knowledge - Who has rights to use it? ILEIA, News Letter, March 1990, p. 24-25.

Gupta, AK. (1995a). People's Knowledge for Survival: Grassroots Innovations for Sustainable Natural Resource Management. In IFAD's International Conference on Hunger \& Poverty in Brussels during November (pp. 16-23).

Gupta, AK. (1995b). In S. Abdus Samad, T. Watanabe, \& S.-J. Kim (Eds.), Sustainable Institutions for Natural Resource Management: How do we participate in people's plans?" by APDC in People's Initiatives for Sustainable Development: Lessons of Experience (Chapter 15, pp. 341-373).

Gupta, AK. (1998). In L. D. Guruswamy \& J. A. McNeely (Eds.), Rewarding Local Communities for Consenving Biodiversity: The Case of the Honey Bee in Protection of Global Biodiversity: Converging Strategies (pp. 180-189). Durham and London: Duke University Press. 
Gupta, AK. (2000). Rewarding Traditional Knowledge and Contemporary Grassroots Creativity:1:The Role of Intellectual Property Protection. www.ksg.harvard.edu/sustsci/ists/TWAS_0202/gupta_0500.pdf.

Gupta, AK. (2002). Rewarding conservation of biological and genetic resources and associated traditional knowledge and contemporary grassroots creativity. Indian Institute of Management. Wipo-Unep Study on the Role of Intellectual Property Rights in the Sharing of Benefits Arising from the Use of Biological Resources and Associated Traditional Knowledge-Study knowledge, based on the data collected from Mali, Nigeria and India (No. 4) (WIPO-UNEP). Geneva: WIPO.

Gupta, AK. (2003). The Role of Intellectual Property Rights in preserving the spirit of Experimentation, Innovation and conservation at Grassroots Level, IPR and Enviorbment (p. 53). Geneva: UNEP.

Gupta, AK. (2006). From sink to source: The Honey Bee Network documents indigenous knowledge and innovations in India. Innovations, 1(3), 49-66.

Gupta, AK. (2007). How local knowledge can boost scientific studies. http:/www.scidev.net/global/bioprospecting/ opinion/how-local-knowledge-can-boost-scientific-studies.html.

Gupta, AK. (2009a) Indian Hidden hotebd of invention, Ted talk. http://www.ted.com/talks/anil_gupta_india_s_hidden_ hotbeds_of_invention?language $=e$ n

Gupta, AK. (2011). Inclusive Innovation for harnessing developmental potential at grassroots, Paper invited for the OECD Global Forum on the Knowledge Economy, Paris.

Gupta, AK. (2012). Innovations for the poor by the poor, Keynote lecture delivered at the Wits University Innovation for Development: Frontiers of Research, Policy and Practice Symposium, Feb 24-26, 2010, Johannesburg, International Journal of Technological Learning. Innovation and Development, 5(1-2), 28-39.

Gupta, AK. (2013). Tapping the entrepreneurial potential of grassroots innovation. Global Perspectives on How Social Innovation Can Promote the Well-Being of Humanity. Sanford Social Innovation Review., 11(3), 18-21.

Gupta, AK (2014a). Tensions in open innovation systems, honey bee network perspective. http://www.slideshare.net/ anilgb/tensions-in-open-innovation-systems-honey-bee-network perspective-akg-2014?qid =60a5c3c9-487b-4874a0ed-89d7d027b97a\&v = \&b = \&from_search $=12$

Gupta, AK (2014b). Fertilizing imagination: From informationto innovation. http://www.slideshare.net/anilgb/fertilizingimagination-july-2014

Gupta, AK. (2014c). Innovation, Investment, Enterprise: Generating Sustainable Livelihood at Grassroots Through Honey Bee Philosophy; Collaboration for Sustainability and Innovation: A Role For Sustainability (Diego A. Vazquez-Brust, Joseph Sarkis, James J. Cordeiro Eds), Greening of Industry Network Studies, Springer. Science + Business Media Dordrecht, 3, 217-232.

Gupta, AK. (2015a). Creating an Innovation Playground: corporations and/with communities, Oct 8, 2015. http://anilg. sristi.org/creating-an-innovation-playground-corporations-andwith-communities/

Gupta, AK. (2015b). A journey of 25, 250, 2500 years...Open source standards of excellence: far into future, (Editorial), Honey Bee Newsleter, special 25th year anniversary issue, 25(4), 26(1), 2015.

Gupta, AK (2016). Designing innovation, insitutions for social transformation. http://www.slideshare.net/anilgb/ designing-innovation-insitutions-for-social-transformation-d1s3-gupta-anil-iciig?qid=60a5c3c9-487b-4874-a0ed89d7d027b97a\&v=\&b=\&from_search $=8$

Gupta, Anil K, 2007, How to protect the Inventions of the poor, http://www.scidev.net/global/knowledge-economy/ opinion/how-to-protect-the-inventions-of-the-poor.html

Gupta, AK, \& Mashelkar, RA. (2005). Women and Formal and Informal Science, IIMA Working Paper No.2005-05-02, May 2005, published in History of Science, Philosophy and Culture in Indian Civilisation (General Editor: D.P. Chattopadhyaya), Volume IX Part 3. In B. Ray (Ed.), Women of India: Colonial and Post-colonial Periods (Vol. Chapter 10, pp. 208-235). New Delhi: Sage Publications India Pvt Ltd.

Gupta, AK, \& Mathur, K. (1984). Action Research for Micro, Level Planning: A Self Appraisal. International Review of Administrative Sciences, L(1), 60-68.

Gupta, AK, \& Sinha, R. (2002). Contested domains, fragmented spaces: rights, responsibilities and rewards for conserving biodiversity and associated knowledge systems". In P. S. Ramakrishnan, R. K. Rai, R. P. S. Katwal, \& S. Mehndiratta (Eds.), Traditional Ecological Knowledge for Managing Biosphere Reserves in South and Central Asia (pp. 161-181). New Delhi: Oxford \& IBH Publishing Co. Pvt Ltd.

How, J. (2006). The rise of Crowdsourcing, Wired Magazine - Issue 14.06 - June 2006. http://www.wired.com/wired/archive/ 14.06/crowds_pr.html.

Hyo, J, Yun, J, Won, D, \& Park, K. (2016). Dynamics from open innovation to evolutionary change. Journal of Open Innovation: Technology, Market, and Complexity Technology, Market, and Complexity, 2, 7. doi:10.1186/s40852-016-0033-0.

Immelt, JR, Govindarajan, V, \& Trimble, C. (2009). How GE is disrupting itself. Harvard Business Review, 87(10), 56-65.

Laursen, K., \& Salter, A. (2006). Open for innovation: the role of openness in explaining innovation performance among U.K. manufacturing firms. Strategic Management Journal, 27, 131-150.

Laursen, K., \& Salter, A. (2014). The paradox of openness: appropriability, external search and collaboration. Research Policy, 43(5), 867-878.

Macnaghten, P, Owen, R, Stilgoe, J, Wynne, B, Azevedo, A, de Campos, A, Chilvers, J, Dagnino, R, di Giulio, G, Frow, E, Garvey, B, Groves, C, Hartley, S, Knobel, M, Kobayashi, E, Lehtonen, M, Lezaun, J, Mello, L, Monteiro, M, Pamplona da Costa, J, Rigolin, C, Rondani, B, Staykova, M, Taddei, R, Till, C, Tyfield, D, Wilford, S, \& Velho, L. (2014). Responsible innovation across borders: tensions, paradoxes and possibilities. Journal of Responsible Innovation, 1(2), 191-199.

Mayer, RC, Davis, JH, \& Schoorman, FD. (1995). An integrative model of organizational trust. Academy of Management Review, 20(3), 709-734.

McDonough, W., \& Braungart, M. (2009). Cradle to cradle: Remaking the way we make things. London: Vintage.

Moritz, M, Redlich, T, Krenz, P, Buxbaum-Conradi, S, \& Wulfsberg, JP. (2015, August). Tesla Motors, Inc.: Pioneer towards a new strategic approach in the automobile industry along the open source movement?. InManagement of Engineering and Technology (PICMET), 2015 Portland International Conference on (pp. 85-92). IEEE.

Owen, R, Stilgoe, J, Macnaghten, P, Gorman, M, Fisher, E, \& Guston, D. (2013). A framework for responsible innovation. Responsible innovation: managing the responsible emergence of science and innovation in society, 27-50 
Pansera, M. (2013). Frugality, Grassroots and Inclusiveness: New Challenges for Mainstream Innovation Theories. African Journal of Science, Technology, Innovation and Development, 5(6), 2013.

Poetz, MK, \& Schreier, M. (2012). The value of crowdsourcing: Can users really compete with professionals in generating new product ideas? Journal of Product Innovation Management, 29(March), 245-256.

Quinn, G, \& Brachmann, S. (2014). Tesla on Patents: Open Source Altruism or Shrewd Business? IP Watchdog. http:// www.ipwatchdog.com/2014/07/08/tesla-on-patents-open-source-altruism-or-shrewdbusiness/id=50331/ Accessed 15 Mar 2016.

Schaarschmidt, M. (2012). Firms in Open Source Software Development Managing Innovation Beyond Firm Boundaries; Gabler Verlag | Springer Fachmedien Wiesbaden.

Sinha, R. (2008). The silent innovators (One India, One People, pp. 15-17).

Urban, GL, \& Von Hippel, E. (1988). Lead user analyses for the development of new industrial products. Management Science, 34(5), 569-582.

Von Hippel, EA. (2002). Open source projects as horizontal innovation networks-by and for users.

Von Hippel, E. (2005). Democratizing innovation: The evolving phenomenon of user innovation. Journal für Betriebswirtschaft, 55(1), 63-78,

Von Hippel, EA, Ogawa, S, \& de Jong, PJ. (2011). The age of the consumer-innovator. MIT Sloan Management Review, 53, 1.

West J, \& Bogers M (2014). Leveraging external sources of innovation: a review of research on open innovation. Journal of Product Innovation Management, 31(4), http://dx.doi.org/10.1111/jpim.12125

West, J, Salterb, A, Vanhaverbekec, W, \& Chesbrough, H. (2014). Open innovation: The next decade. Research Policy, 43(5), 805-811.

Yun, J, \& Avvari, M (2012). Exploring open innovation approaches adopted by small and medium firms in emerging/ growth industries: Case studies from Daegu-Gyeongbuk region of South Korea. International Journal of Technology, Policy and Management, 12(1), 1-19. doi:10.1504/ITPM.2012.044965. January 2012.

Yun, Jin Hyo Joseph, Seung-Ku Ahn and Avvari Mohan (2010). Open Innovation in Small and Medium Industry: case stuids from South Korea, 8th th International Globelics conference, Malaysia

Submit your manuscript to a SpringerOpen ${ }^{\circ}$ journal and benefit from:

- Convenient online submission

- Rigorous peer review

- Immediate publication on acceptance

- Open access: articles freely available online

- High visibility within the field

- Retaining the copyright to your article

Submit your next manuscript at $>$ springeropen.com 